\title{
ANALYSIS OF MASONRY STRUCTURES UNDER STATIC AND DYNAMIC LOADING BY DISCRETE FINITE ELEMENT METHOD
}

\author{
Iraj H. P. MAMAGHANI ${ }^{1}$, Ömer AYDAN ${ }^{2}$ and Yasuo KAJIKAWA ${ }^{3}$ \\ ${ }^{1}$ Member of JSCE, Dr. of Eng., Assistant Professor, Dept. of Civil Eng., Kanazawa University \\ (Kodatsuno 2-40-20, Kanazawa 920-8667, JAPAN) \\ ${ }^{2}$ Member of JSCE, Dr. of Eng., Associate Professor, Dept. of Marine Civil Eng., Tokai University \\ (Orido 3-20-1, Shimizu 424, JAPAN) \\ ${ }^{3}$ Member of JSCE, Dr. of Eng., Professor, Dept. of Civil Eng., Kanazawa University
}

(Kodatsuno 2-40-20, Kanazawa 920-8667, JAPAN)

\begin{abstract}
A technique based on the principles of finite element method incorporating the contact element, called discrete finite element method (DFEM), to model masonry structures consisting of blocks of arbitrary shapes is developed and adopted in the static and dynamic analyses of masonry structures. The DFEM considers blocks as sub-domains and represents them by solid elements. Contact elements, which are far-superior to joint or interface elements, are used to model the block interactions such as sliding or separation. The applicability of the DFEM to static and dynamic analyses of structures such as towers, walls and arches of masonry type are checked and discussed.
\end{abstract}

\section{Key Words : discrete finite element method, analysis, masonry structures, static, dynamic}

\section{INTRODUCTION}

Masonry structures, consisting of interacting distinct blocks, have been constructed since the earliest days of civilization. They are still commonly practiced in many countries all over the world and constitute a significant percentage of the current civil engineering structures stock. Many of these structures are located in seismic regions and were built before the establishment of any design-code requirements for earthquake resistant construction. Compared with modern structures built of materials with well understood constitutive laws, the mechanics of masonry structures are still not clearly understood in spite of their long use in civil engineering history. The failures and damages reported in recent earthquakes attest to the need for efficient strengthening procedures and therefore an efficient analytical method for analysis of masonry structures.

The analyses of masonry structures has been receiving a particular interest among civil engineers. In recent years, several techniques have been developed to analyze rock masses consisting of distinct blocks in the field of rock mechanics. The limiting equilibrium analysis ${ }^{1), 2)}$ and some numerical analysis methods such as the finite element method (FEM) with joint or interface element ${ }^{3)-5)}$, distinct element method $(\mathrm{DEM})^{6)}$, and discontinuities deformation analysis $(\mathrm{DDA})^{7)}$ can be accounted for. In spite of all these techniques, it is difficult to say that a unique technique, that guarantees satisfactory results, is developed. Although DEM and DDA can be used for static and dynamic analyses of masonry structures, the treatment of ratedependent behavior of materials in these methods is nothing to do with the actual ones. For example, DEM introduces a forced damping to suppress oscillations. DDA adopts very large time steps so that artificial damping occurs as a results of numerical integration. 
Mamaghani and Aydan proposed the discrete finite element method (DFEM) for blocky systems under static loading which is based on the principles of the finite element method $^{8)-12)}$. In this study, the DFEM is extended and applied to the analyses of masonry structures under dynamic loading. It consists of a mechanical model to represent the deformable blocks and contact models that specify the interaction among them. In the DFEM, a visco-elastic constitutive law for linear behavior and a visco-elasto-plastic constitutive law for nonlinear behavior of blocks and contacts are used together with the updated Lagrangian scheme. The DFEM can handle with large block motions within the framework of the finite element method. In this paper, first the modeling of block contact discontinuities and DFEM formulation are presented. Then, the DFEM is used to analyze static and dynamic responses of some typical masonry structures, such as, one block on an incline, arches, pyramids, walls, and towers. Some of the results are compared with those obtained from other techniques and the applicability of the DFEM to static and dynamic analyses of such structures are checked and discussed.

\section{MODELING OF BLOCK CONTACT DISCONTINUITIES}

Discontinuum is distinguished from continuum by the existence of discontinuities at contacts between the discrete bodies that comprise the system. The actual geometry of contacts are never smooth and has asperities of varying amplitude and wave length ${ }^{5), 13)-15)}$. Relative sliding or separational movements in such localized zones present an extremely difficult problem in mechanical modeling and numerical analysis. The formulation for representing contacts is very important when a system of interacting blocks is considered, and it has been receiving a considerable interest among researchers.

There are two fundamental theoretical models, namely Hertz's model and Mindlin's model ${ }^{16)}$, for modeling contacts. However, these models are restricted to a very simple geometry and the elastic behavior of adjacent materials. Since the configuration of contacts and the mechanical behavior of adjacent materials are generally complex, the experimental techniques is probably the only way to deal with contact problems. In this respect, the direct shear test technique is one of the most suitable techniques to characterize the behavior of contacts.

There have been mainly three kinds of modeling to interpret and to utilize the responses measured in direct shear tests:

1. Force-displacement type modeling ${ }^{6), 17)}$,

2. Stress-displacement type modeling ${ }^{3}$, and

3. Stress-strain type modeling (band type modeling) ${ }^{4), 5), 13)}$

In Force-displacement type modeling, contacts are assumed to have a zero thickness without an explicit definition of contact area $A_{c}$. The responses measured in direct shear tests are directly used in numerical representations. As the responses are likely to differ depending upon the size of specimens in tests, it is not a universal and objective approach.

The second type modeling is probably the most widely used approach in numerical analyses. The contacts are again assumed to have a zero thickness. Although it is much better than the first type modeling, the test results are likely to be influenced by the sample size and it is still a subjective one.

The most suitable and mechanically sound approach is the band type modeling. Contacts are considered as bands with a finite thickness. The thickness of the bands is related to the thickness of shear-bands observed in tests or in nature, and if exists, the height of asperities along the plane ${ }^{5), 13), 14)}$. For an idealized contact shown in Fig. 1, the average normal and shear stresses and strains are defined as follow:

$$
\sigma_{n}=\frac{F_{n}}{A}, \quad \varepsilon_{n}=\frac{\delta_{n}}{h}, \tau_{s}=\frac{F_{s}}{A}, \gamma_{s}=\frac{\delta_{s}}{h}
$$

where $A$ and $h$ are the area and the thickness of the band; $F_{n}$ and $F_{s}$ stand for the normal and tangential forces; and $\delta_{n}$, and $\delta_{s}$ denote the normal and tangential deformations, respectively (see Fig. 1). Furthermore, it is also possible to define the average strain rates $\dot{\varepsilon}_{n}$ and $\dot{\gamma}_{s}$. As a result, this model also enables one to define stressstrain rate dependent responses, objectively. The problem is, then, to select a constitutive model such as an elastic, elasto-plastic or elasto-visco- 

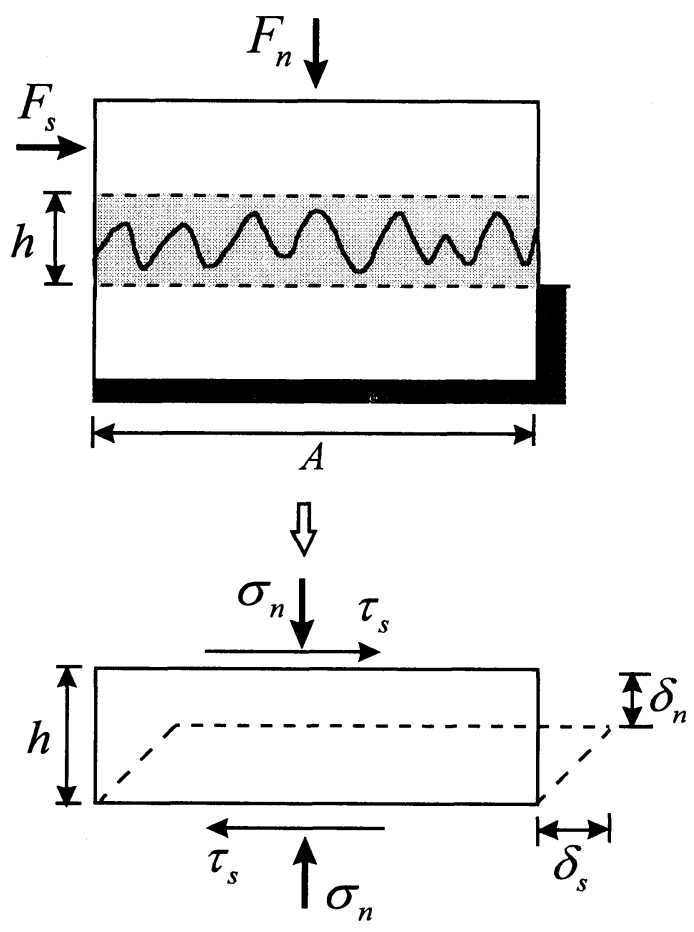

Fig. 1 Mechanical model of a contact as a band

plastic type constitutive law which is appropriate for modeling the mechanical behavior of contacts.

\section{DISCRETE FINITE ELEMENT METHOD (DFEM)}

The DFEM suggested in this study, in assessing the stability of rock block systems, is based on the finite element method. It consists of a mechanical model to represent the deformable blocks and contact models that specify the interaction among them. The deformation of blocks is assumed to be small unless they are allowed to rupture. Small displacement theory is applied to the deformable blocks while blocks can take finite displacement. The large deformation of blocky systems is associated with the separation, translation and rotation of blocks. Blocks are polygons with an arbitrary number of sides which are in contact with the neighboring blocks, and are idealized as a single or multiple finite elements. Block contacts are represented by a contact element.

\section{(1) Mechanical modeling}

The general equation of motion is given by

$$
\boldsymbol{\nabla} \cdot \boldsymbol{\sigma}+\boldsymbol{b}=\rho \ddot{\boldsymbol{u}}
$$

where $\boldsymbol{\sigma}, \boldsymbol{b}, \rho, \boldsymbol{u} \boldsymbol{u}$ are stress tensor, body force, density and acceleration respectively.

The following presentation is restricted to the framework of the small-strain theory. The straindisplacement relations are:

$$
\varepsilon=\frac{1}{2}\left(\nabla u+(\nabla u)^{T}\right)
$$

The strain rate-velocity relations are:

$$
\dot{\boldsymbol{\varepsilon}}=\frac{1}{2}\left(\boldsymbol{\nabla} \boldsymbol{v}+(\boldsymbol{\nabla} \boldsymbol{v})^{T}\right)
$$

where $\boldsymbol{v}=\dot{\boldsymbol{u}}$.

The following constitutive relationship among stresses and strains and strain rates holds:

$$
\boldsymbol{\sigma}=\boldsymbol{D}_{e} \boldsymbol{\varepsilon}+\boldsymbol{D}_{v} \dot{\boldsymbol{\varepsilon}}
$$

where $\boldsymbol{D}_{e}$ and $\boldsymbol{D}_{v}$ are elasticity and viscosity tensors ${ }^{18)}$. However, they can be replaced by elasto-plastic and visco-plastic tensors if necessary. This type constitutive law allows us to model intact blocks as well as contacts, interfaces or rock discontinuities.

The boundary conditions are

$$
\boldsymbol{u}=\hat{\boldsymbol{u}} \text { on } \Gamma_{u}, \quad \hat{\boldsymbol{t}}=\boldsymbol{\sigma} \cdot \boldsymbol{n} \text { on } \Gamma_{t}
$$

where $\hat{\boldsymbol{t}}$ is the surface traction in the $n$ direction on boundary $\Gamma_{t}$ and $\hat{\boldsymbol{u}}$ is the displacement on boundary $\Gamma_{u}$. While initial conditions are

$$
\boldsymbol{u}_{\mathrm{o}}, \quad \dot{\boldsymbol{u}}_{0} \quad \text { at } \mathrm{t}=0
$$

\section{(2) Finite element modeling}

In the followings, the finite element form of the equation of motion is derived. Taking a variation on $\delta \boldsymbol{u}$, the following integral form of the Eq. (2) can be written as

$$
\begin{array}{r}
\int_{\Omega}(\boldsymbol{\nabla} \cdot \boldsymbol{\sigma}) \cdot \delta \boldsymbol{u} d \Omega+\int_{\Omega} \boldsymbol{b} \cdot \delta \boldsymbol{u} d \Omega= \\
\int_{\Omega} \rho \ddot{\boldsymbol{u}} \cdot \delta \boldsymbol{u} d \Omega
\end{array}
$$

With the use of the Gauss divergence theorem and the boundary conditions, the weak form of the governing equation takes the following form:

$$
\begin{aligned}
& \int_{\Gamma_{\boldsymbol{t}}} \hat{\boldsymbol{t}} \cdot \delta \boldsymbol{u} d \Gamma+\int_{\Omega} \boldsymbol{b} \cdot \delta \boldsymbol{u} d \Omega= \\
& \int_{\Omega} \boldsymbol{\sigma} \cdot(\nabla \delta \boldsymbol{u}) d \Omega+\int_{\Omega} \rho \ddot{\boldsymbol{u}} \cdot \delta \boldsymbol{u} d \Omega
\end{aligned}
$$

Eq. (7) is discretized in space domain by assuming displacements are approximated by the 
following expression

$$
\boldsymbol{u}=\boldsymbol{N} \boldsymbol{U}(t)
$$

where $\mathbf{N}$ is the shape function. Using the above approximate form and the constitutive law the following expressions in a condensed form are obtained for a typical finite element ${ }^{8)}$

$$
\boldsymbol{M} \ddot{U}+\boldsymbol{C} \dot{U}+\boldsymbol{K} \boldsymbol{U}=\boldsymbol{F}
$$

where

$$
\begin{gathered}
M=\int_{\Omega_{e}} \rho \boldsymbol{N}^{T} \boldsymbol{N} d \Omega, C=\int_{\Omega_{e}} \boldsymbol{B}^{T} \boldsymbol{D}_{v} \boldsymbol{B} d \Omega \\
\boldsymbol{K}=\int_{\Omega_{e}} \boldsymbol{B}^{T} \boldsymbol{D}_{e} \boldsymbol{B} d \Omega \\
\boldsymbol{F}=\int_{\Omega_{e}} \boldsymbol{N}^{T} \boldsymbol{b} d \Omega+\int_{\Gamma_{t e}} \overline{\mathbf{N}}^{T} \mathbf{t} d \Gamma
\end{gathered}
$$

\section{(3) Finite element modeling of block contacts}

The contact element is used to model block contacts. Let us now consider a two-nodded element $(l, m)$ in a two-dimensional space and take two coordinate systems $(o x y)$ and $\left(o^{\prime} x^{\prime} y^{\prime}\right)$ as shown in Fig. 2.

Assuming that, the strain component $\varepsilon_{y^{\prime} y^{\prime}}$ is negligible, the remaining strain components take the following form:

$$
\varepsilon_{x^{\prime} x^{\prime}}=\frac{\partial u^{\prime}}{\partial x^{\prime}}, \quad \gamma_{x^{\prime} y^{\prime}}=\frac{\partial v^{\prime}}{\partial x^{\prime}}
$$

Let us assume that the shape functions are linear such that:

$$
N_{l}=\frac{1}{2}(1-\xi), \quad N_{m}=\frac{1}{2}(1+\xi)
$$

where $\xi=\left(-2 x^{\prime}+x_{l}^{\prime}+x_{m}^{\prime}\right) / L, L=\left(x_{l}^{\prime}-x_{m}^{\prime}\right)$. Then, the relation between the strains and nodal displacements becomes

$$
\left\{\begin{array}{c}
\varepsilon_{x^{\prime} x^{\prime}} \\
\gamma_{x^{\prime} y^{\prime}}
\end{array}\right\}=\frac{1}{L}\left[\begin{array}{cccc}
-1 & 0 & 1 & 0 \\
0 & -1 & 0 & 1
\end{array}\right]\left\{\begin{array}{c}
U_{l}^{\prime} \\
V_{l}^{\prime} \\
U_{m}^{\prime} \\
V_{m}^{\prime}
\end{array}\right\}
$$

Thus, the stiffness matrix of contact element in the local coordinate system is explicitly obtained as

$$
\boldsymbol{K}^{\prime}=\left[\begin{array}{cccc}
k_{n}^{\prime} & 0 & -k_{n}^{\prime} & 0 \\
0 & k_{s}^{\prime} & 0 & -k_{s}^{\prime} \\
-k_{n}^{\prime} & 0 & k_{n}^{\prime} & 0 \\
0 & -k_{s}^{\prime} & 0 & k_{s}^{\prime}
\end{array}\right]
$$

in which

$$
k_{n}^{\prime}=E_{n} \cdot \frac{A_{c}}{x_{m}^{\prime}-x_{l}^{\prime}}, \quad k_{s}^{\prime}=G_{s} \cdot \frac{A_{c}}{x_{m}^{\prime}-x_{l}^{\prime}}
$$

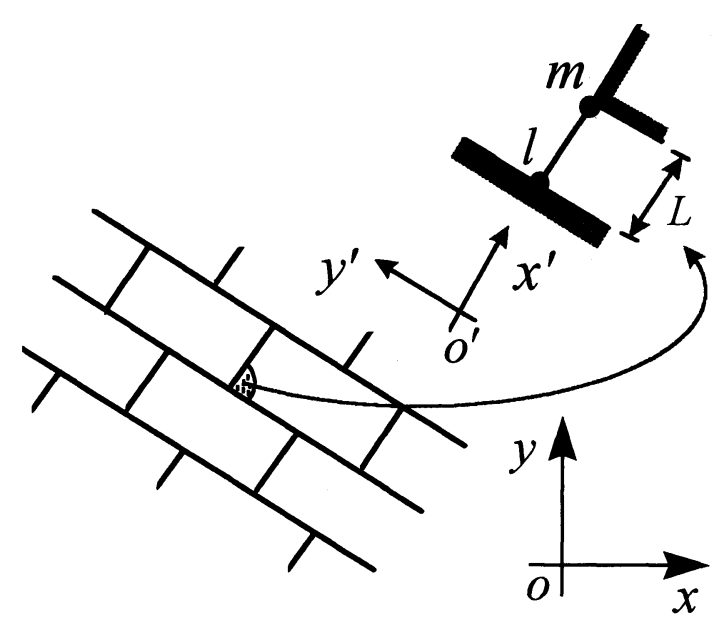

Fig. 2 Finite element modeling of a contact

where $A_{c}$ is the contact area, $E_{n}$ and $G_{s}$ are normal and shear elastic moduli of discontinuity, respectively.

The stiffness matrix in the local coordinate system is then transformed to the stiffness matrix in the global coordinate system by the following relationship

$$
K=T^{T} K^{\prime} T
$$

where

$$
\begin{gathered}
\boldsymbol{T}=\left[\begin{array}{cccc}
\cos \theta & \sin \theta & 0 & 0 \\
-\sin \theta & \cos \theta & 0 & 0 \\
0 & 0 & \cos \theta & \sin \theta \\
0 & 0 & -\sin \theta & \cos \theta
\end{array}\right] \\
\theta=\tan ^{-1}\left(\frac{y_{m}-y_{l}}{x_{m}-x_{l}}\right)
\end{gathered}
$$

The viscosity (damping) matrix of contact element in local coordinate system can be also obtained in a similar manner as given below

$$
C^{\prime}=\left[\begin{array}{cccc}
c_{n}^{\prime} & 0 & -c_{n}^{\prime} & 0 \\
0 & c_{s}^{\prime} & 0 & -c_{s}^{\prime} \\
-c_{n}^{\prime} & 0 & c_{n}^{\prime} & 0 \\
0 & -c_{s}^{\prime} & 0 & c_{s}^{\prime}
\end{array}\right]
$$

in which

$$
c_{n}^{\prime}=E_{n}^{*} \cdot \frac{A_{c}}{x_{m}^{\prime}-x_{l}^{\prime}}, \quad c_{s}^{\prime}=G_{s}^{*} \cdot \frac{A_{c}}{x_{m}^{\prime}-x_{l}^{\prime}}
$$

where $E_{n}^{*}$ and $G_{s}^{*}$ are normal and shear viscosity moduli of discontinuity, respectively. In the above equations, the values of coefficients in the stiffness and viscosity matrices, as well as the 
value of $\theta$ are affected by updating geometrical changes of blocks and contacts.

It is worth noting that on the basis of simplification of the finite element modeling of block contacts, using the small strain theory for modeling of the large deformation, a small error is always present on the computed strains of contacts. Nevertheless, such an error is quite negligible as the geometry of the block system is incrementally updated, which allows to take into account the effect of higher order terms in the definition of finite strain tensor.

\section{NUMERICAL RESULTS AND DISCUSSIONS}

In this section, some typical numerical results of masonry structures obtained by the DFEM will be presented and discussed. In the numerical study, when the inertia term is considered, contacts and blocks are assumed to behave as an elasto-visco-plastic material or a visco-elastic material. On the other hand, if the inertia term is omitted, then the behavior of contacts and blocks are assumed to be elasto-plastic or elastic.

In all analyses reported herein, tensile strength of contact element was assumed to be zero. Mohr-Coulomb yield criterion was implemented in the present codes. Nevertheless, one can easily implement any yield criterion, which is appropriate for the plastic or visco-plastic behavior. Contact area $A_{c}$ was assumed to be a half of the area of the side of a block to which the contact element is attached. The thickness of the bands was taken as twice the weighted asperity height. Taking into account the results reported by Aydan and Shimizu ${ }^{15)}$, the thickness of the bands was selected as $10 \mathrm{~mm}$. The secant stiffness method together with updated Lagrangian Scheme was employed to deal with non-linear behavior. The constant strain triangular element with two degrees of freedoms at each node, formed by properly joining the corners and contact nodes of an individual block, was adopted for finite element meshing of the blocks ${ }^{8)}$. However, it must be noted that the method is not restricted to the use of such elements and one can easily implement finite elements of chosen nodes.

The flow chart for static analysis is shown in Fig. 3. The analysis is a pseudo time stepping

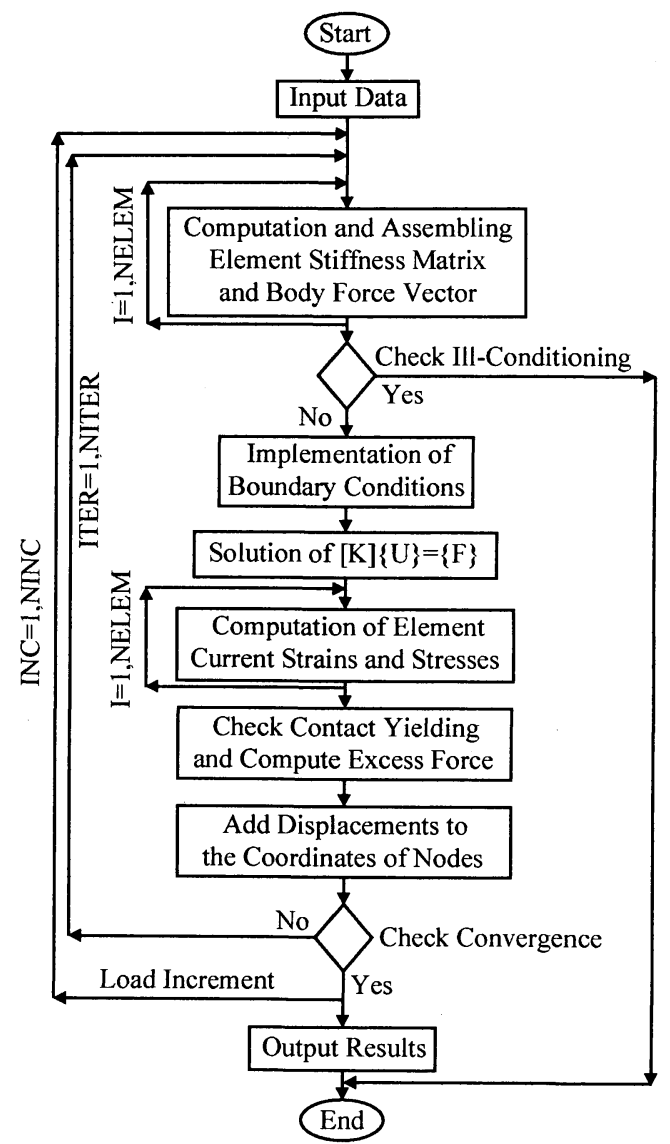

Fig. 3 Flow chart

incremental procedure. First the initial configuration of the structural system, boundary conditions and material properties are input. Then iterations are carried out by forming the global stiffness matrix and solving equilibrium equations of the system. Later the strains and stresses of elements are computed. The no-tension condition and Mohr-Coulomb's yield criterion are checked and the excess forces at contacts are applied to the updated configuration as the penalty load in the subsequent iteration until the norm of excess force vector converges to a very small value of convergence tolerance. The computation is terminated when a stable configuration is achieved or the global stiffness matrix becomes ill-conditioned as single or multiple blocks tends to move without any interaction with each other corresponding to the failure of the system. The details of the numerical algorithm and computational procedure are given in the work by Mamaghani ${ }^{8}$. 


\section{(1) Analysis of masonry structures under static loading}

In the case of all numerical analysis under static loading, the material properties of intact blocks; Lame's constants $\lambda=56 \mathrm{GPa}$ and $\mu=21$ $\mathrm{GPa}$, and unit weight $\rho=25 \mathrm{kN} / \mathrm{m}^{3}$ and the properties of contacts; normal stiffness $E_{n}=50$ $\mathrm{GPa}$ and shear stiffness $G_{s}=0.5 \mathrm{GPa}$ are used.

\section{a) Stability of one block on an incline}

A very simple, yet meaningful problem analyzed by the DFEM is the stability of one block on an incline. The theoretical kinematic conditions for sliding and toppling of one block on an incline, under gravity, have been given in a chart by Hoek and Bray ${ }^{1)}$ (hereafter referred to as H-B chart). The $\mathrm{H}-\mathrm{B}$ chart with the friction angle between the block and the incline $\phi=20^{\circ}$ is shown in Fig. 4. In the H-B chart, four modes of behavior, namely, (a) stability, (b) sliding without toppling, (c) sliding and toppling, and (d) toppling without sliding are delineated by four boundaries I, II, III and IV. The DFEM is applied to study the stability of one block on an incline, and the results are compared with those predicted by the H-B chart.

For a methodical comparison, the slope angle, $\alpha$, and the aspect ratio of the block, $\gamma=$ $\arctan (b / d),(b=$ breadth; $d=$ height of the block, see Fig. 4) were varied systematically, while friction angle, $\phi$, was fixed at $20^{\circ}$. Different symbols representing different modes of behavior obtained by the DFEM are plotted on the H-B chart as shown in Fig. 4. As can be seen from these plots, the results by the proposed method are in complete agreement with the theoretical results. Since the validity of the theoretical solutions are also validated by experiments ${ }^{1), 2)}$, it can be concluded that the DFEM is a promising method for studying the mechanics of blocky media. It is worth noting that the results for total behavior of a block or a pile of blocks on an incline are given in the authors previous works ${ }^{9), 12)}$.

\section{b) Masonry arch}

As a second example, the stability analysis of a masonry arch structure is considered. The dimension of the blocks perpendicular to the $x y$ plane is taken as $w=1.0 \mathrm{~m}$, see Fig. 5. The arch is stable under its own weight. It is still stable when the distributed uniform traction force per unit horizontal area over the arch is less (a) $\square$ Stable, (b) $\Delta$ Sliding, (c) $\diamond$ Toppling-Sliding, (d) $\bigcirc$ Toppling

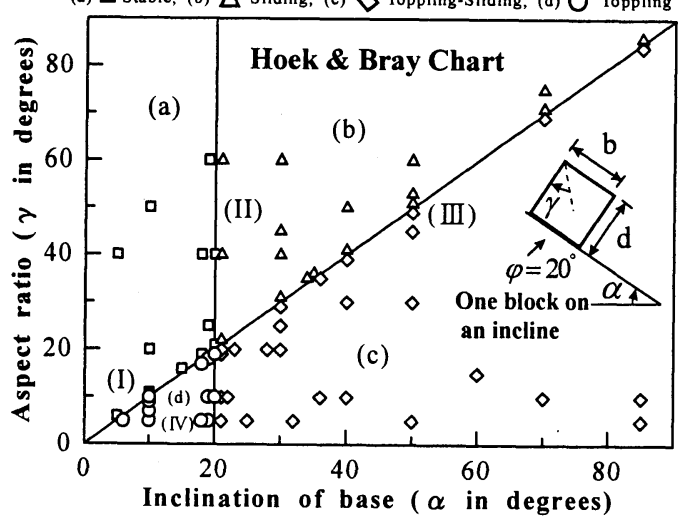

Fig. 4 Kinematic conditions of one block on an incline (DFEM versus theoretical results)
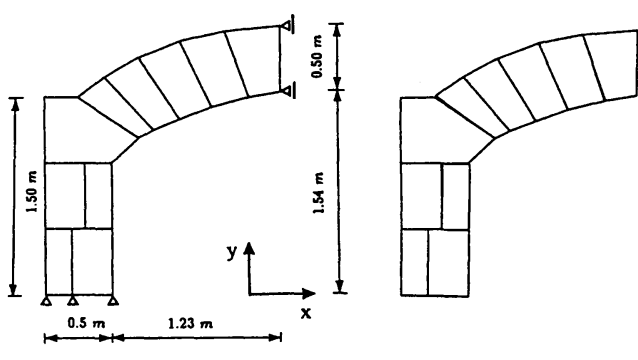

Initial configuration

Iteration No. 24

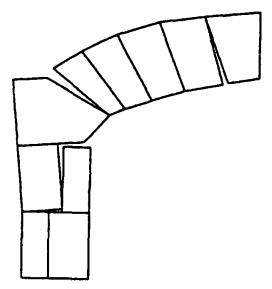

Iteration No. 27

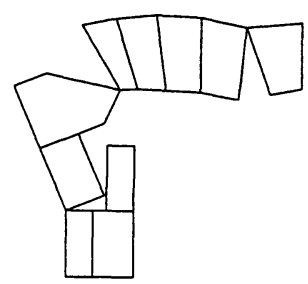

Iteration No. 30
Fig. 5 Failure mode of a masonry arch

than $1.47 \mathrm{kN} / \mathrm{m}^{2}$. However, if the traction force reaches that level, then the arch starts to be unstable. Fig. 5 shows the configurations of the arch at different iterations which may be regarded as fictitious time.

\section{c) Masonry pyramid}

In the next example, a masonry pyramid structure was analyzed. The dimension of the blocks perpendicular to the $x y$ plane is taken as $w=1.0$ $\mathrm{m}$, see Fig. 6. This structure is found to be stable under its own weight and for small values of lateral loads $F_{1}$ and $F_{2}$ which are applied at a 
Initial configuration

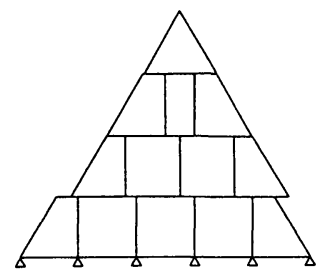

Iteration No. 13

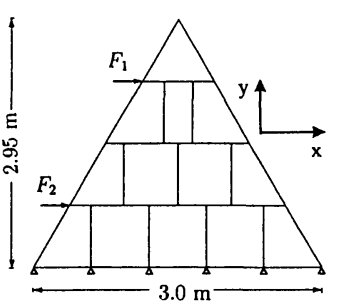

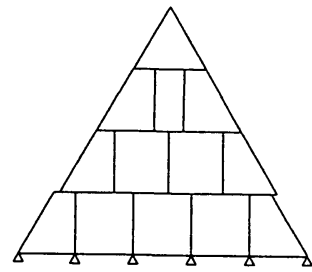

Iteration No. 11

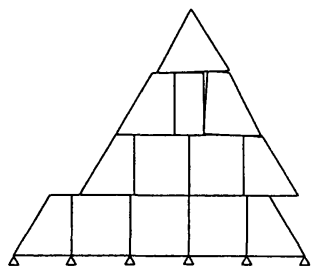

Iteration No. 15
Fig. 6 Failure mode of a masonry pyramid

single step and are equally shared with two corner nodes of the upper and lower blocks in contact at the location of applied loads as shown in Fig. 6. However, the configuration becomes unstable when the lateral loads are increased to $F_{1}=4.9$ $\mathrm{kN}$ and $F_{2}=127.4 \mathrm{kN}$. The failure mechanism is shown in Fig. 6. As seen from the figure, blocks slide and some of the contacts are separated with the increasing number of iterations.

\section{(2) Analysis of masonry structures under dynamic loading}

This section is concerned with several applications of the DFEM to dynamic analysis of masonry structures. In the analysis, the foundation of the structures was subjected to two types of lateral acceleration waves; Acc. No. 1 with a large period:

$$
A c c=0.8 t e^{-0.5 t} \sin (t) \times 981
$$

and Acc. No. 2 with a small period:

$$
A c c=0.8 t e^{-0.5 t} \sin (3 t) \times 981
$$

in which $t=$ time and $A c c=$ lateral acceleration in gal, as shown in Fig. 7. The assumed accelerations are used to check the response of analyzed masonry structures by DFEM under two different wave forms. The material and mechanical properties of blocks, foundations and contacts
Table 1 Material properties of rock blocks and contacts

\begin{tabular}{lclc}
\hline \multicolumn{2}{c}{ Rock Blocks } & \multicolumn{2}{c}{ Contacts } \\
\hline Parameter & Value & Parameter & value \\
\hline$\lambda(M P a)$ & 30 & $E_{n}(M P a)$ & 5.0 \\
$\mu(M P a)$ & 30 & $G_{s}(M P a)$ & 2.5 \\
$\lambda^{*}(M P a . s)$ & 30 & $E_{n}^{*}(M P a . s)$ & 5.0 \\
$\mu^{*}(M P a . s)$ & 30 & $E_{s}^{*}(M P a . s)$ & 2.5 \\
$\rho\left(k N / m^{3}\right)$ & 25 & $h(m m)$ & 5.0 \\
& & $\phi\left(^{\circ}\right)$ & 35 \\
\hline
\end{tabular}
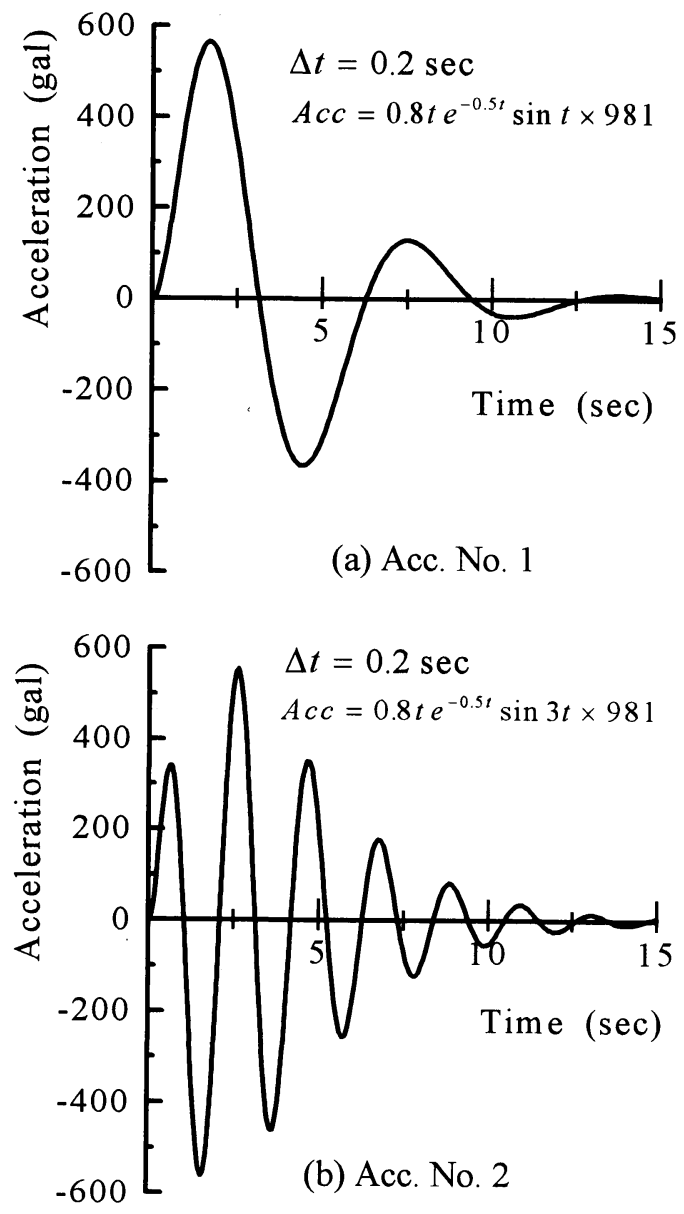

Fig. 7 Imposed lateral acceleration waves on foundation

are given in Table 1, where $\lambda$ and $\mu$ denote Lame's constants, and $\rho, E_{n}, G_{s}^{\prime}, h$ and $\phi$ indicate unit weight of rock mass, elastic modulus, shear modulus, band width of contact elements and friction angle, respectively. In all examples, the time step was chosen as 0.2 second. 
a) Masonry tower

Figs. 8(a), 8(b) and $8(c)$ show the initial and deformed configurations of a masonry tower at the time steps of 22 (4.4 seconds) and 50 (10 seconds) corresponding to the Acc. No. 1 and Acc. No. 2, respectively. For plotting the initial and deformed configurations (see Fig. 8(a)), in this example and all examples reported hereafter, the displacement in the deformed configurations is amplified by 50 times to make more visible the mode of failure (deformed configuration) from the initial configuration. Fig. 8(b) shows that when the tower is subjected to Acc. No. 1, there is a sliding at the base of the tower at time step 22 and the most upper blocks start to detach at the top of the tower. At time step 50, relative sliding and separation occurs along block contacts and the two most upper blocks tend to topple in two opposite directions. Fig. 8(c) shows that, under Acc. No. 2, there is no sliding of the tower at the base while the most upper blocks of the tower are separated and tends to topple at time step 22. At time step 50, there is a relative slide at the base of the tower and blocks are slid and detached along block contacts. Fig. 9 shows the displacement response versus the number of time step for a nodal point at the top most right corner of the tower (monitoring node) corresponding with both of the imposed acceleration waves. As shown in Fig. 9, the toppling of the top mostright block of the tower is more severe under Acc.

No. 1 as compared with the Acc. No. 2.

Comparison of the responses in Figs. 8 and $\mathbf{9}$ also show that the failure mode of the tower depends to the nature of the imposed acceleration wave. The tower shows relatively stable behavior under Acc. No. 2 with a small period as compared with that of the Acc. No. 1 with a large period at the time step 22. However, the tower does not return to its original position and ceases to be stable at the end of shaking under both of the imposed form of the acceleration waves, see Fig. 8 for time step 50. It is worth noting that, as shown in Fig. 8, the response of the tower is quite similar to those may be expected in actual earthquakes.

\section{b) Masonry wall}

Figs. 10(a), 10(b) and 10(c) show the initial and deformed configurations of a masonry wall subjected to the Acc. No. 1 at time steps of 22

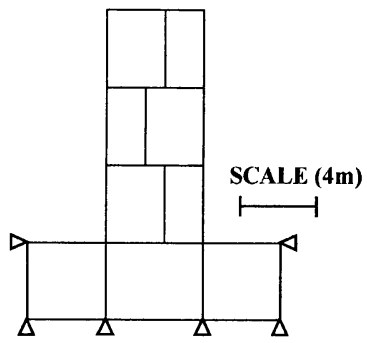

(a) Initial Configuration

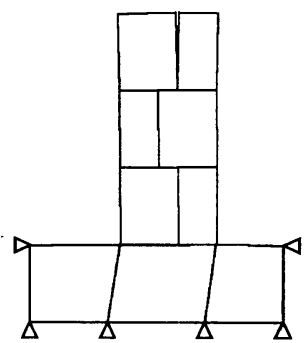

Time step 22

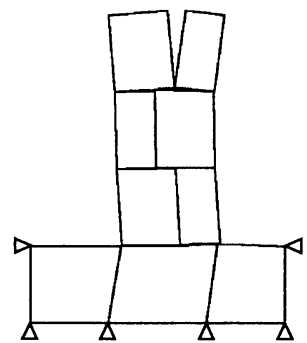

Time step 50 (b) Acc. No. 1

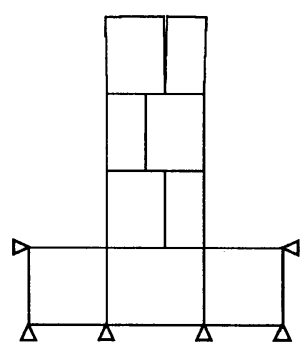

Time step 22

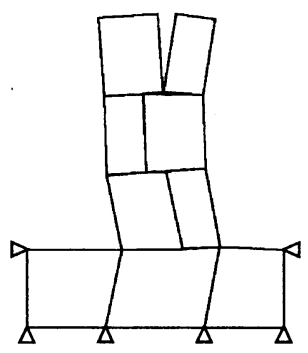

Time step 50 (c) Acc. No. 2

Fig. 8 Initial and deformed configurations of the masonry tower

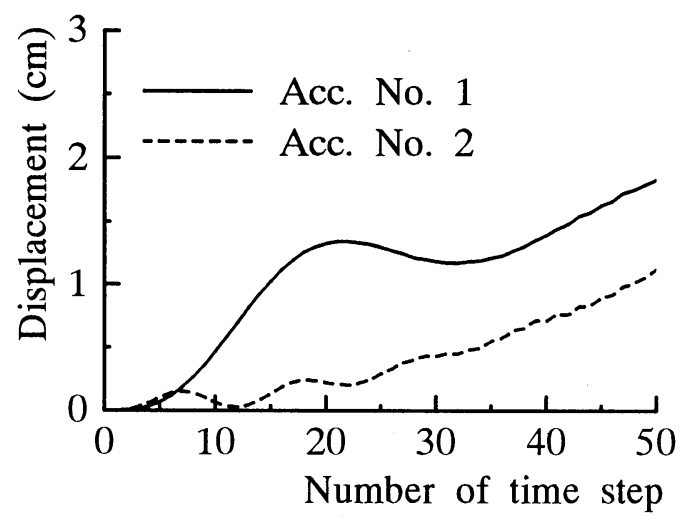

Fig. 9 Displacement response with time at the top mostright corner of the tower 


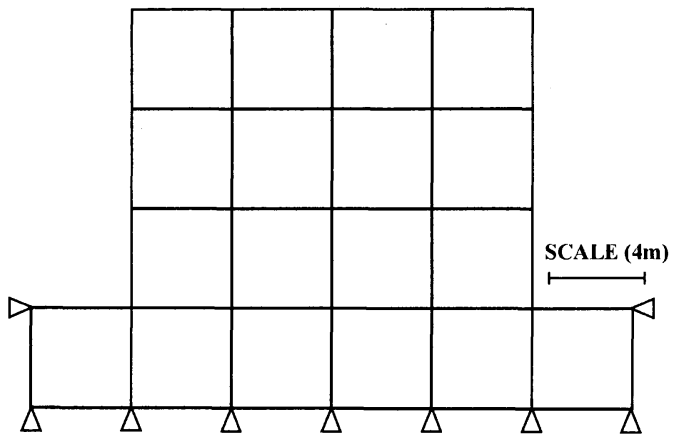

(a) Initial configuration

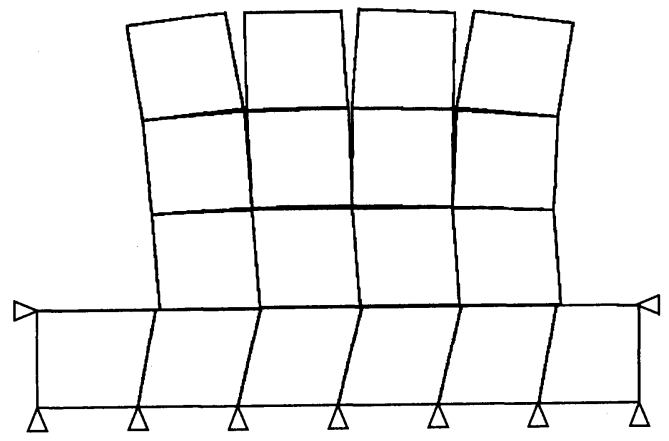

(c) Time step 50 (10 seconds)

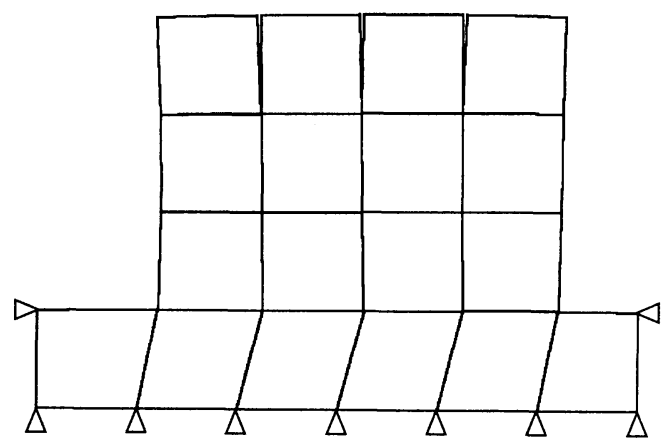

(b) Time step 22 (4.4 seconds)

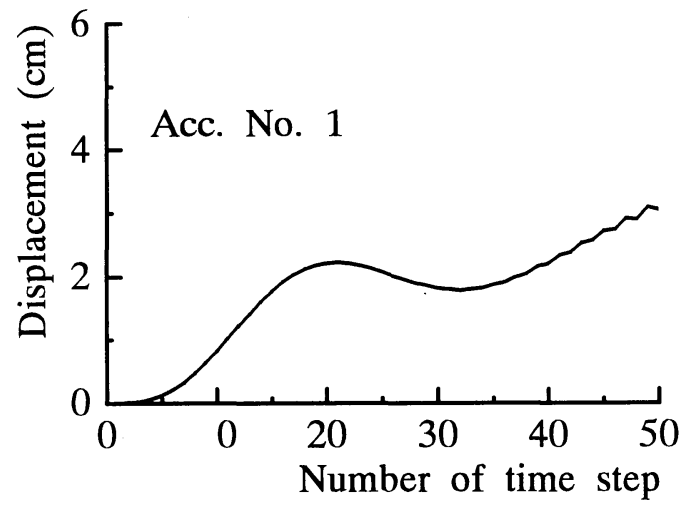

(d) Response of the top most-right corner

Fig. 10 Initial and deformed configurations and displacement response with time of the masonry wall under Acc. No. 1

(4.4 seconds) and 50 (10 seconds), respectively. The displacement response for a nodal point at the top most-right corner of the wall with time is shown in Fig. 10(d). As shown in Fig. 10(b), there is a sliding at the base of the wall at time step 22 and detaching of the blocks occurs starting from the top of the wall. At the time step of 50 (10 seconds), there is a relative sliding at the base of the wall and separation and rotation of blocks occur within the wall, see Figs. 10(c) and 10(d). The blocks within the wall are separated along the vertical discontinuities and are formed columns which tend to topple in two opposite directions. The tendency of toppling is more severe for the most outer columns as compared with the inner columns, as shown in Fig. 10(c) .

\section{c) Masonry arch}

Figs. 11(a), 11(b) and 11(c) show the initial and deformed configurations of a masonry arch at the time steps of 23 (4.6 seconds) and 50 (10 seconds) subjected to the Acc. No. 1 and Acc. No. 2, respectively. Fig. 11(b) shows that the arch is slid at the base at the time step 23 under Acc. No. 1 and the crown blocks of the arch starts to fall apart while the side columns are still stable. Fig. 11(b) shows that, under Acc. No. 1 at the time step 50, the arching action disappears and the crown blocks fall apart. The columns slide relative to the base and they tend to topple in two opposite directions. The blocks tend to separate within the side columns, see Fig. 11(b) for the time step 50.

Fig. 11(c) shows that, under Acc. No. 2 at the time step 23, there is no slide at the base of the arch while the crown blocks are separated and tend to fall apart. At the time step 23, the side columns of the arch exhibit relatively stable behavior under Acc. No. 2 as compared with the Acc. No. 1, see Figs. 11(b) and 11(c). However, under Acc. No. 2 at the time step 50 


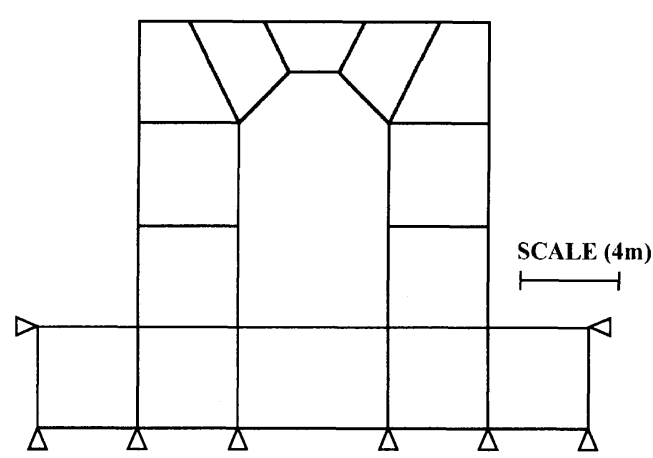

(a) Initial configuration

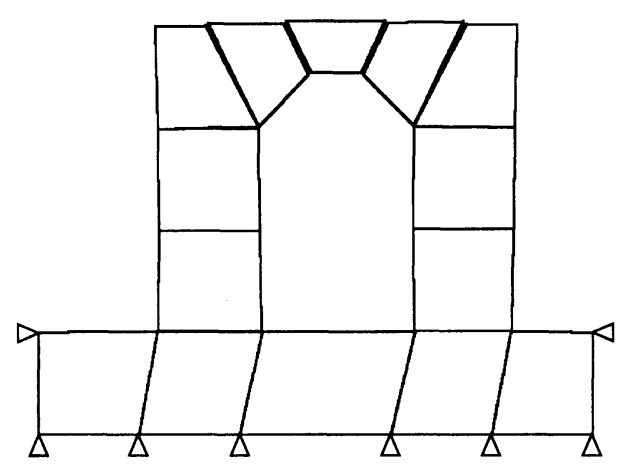

Time step 23 (4.6 seconds)

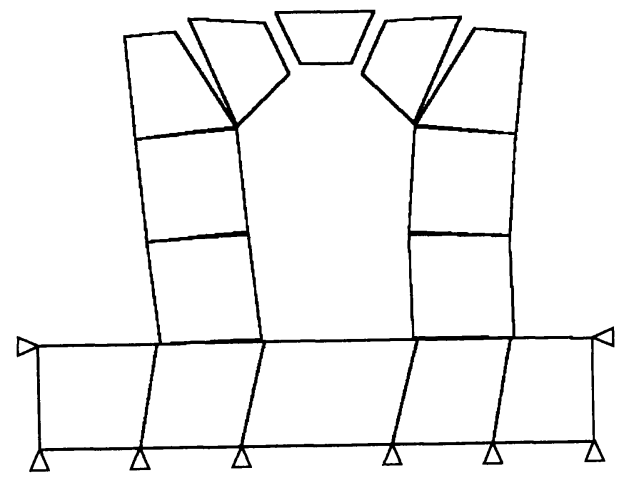

Time step 50 (10 seconds)

(b) Acc. No. 1

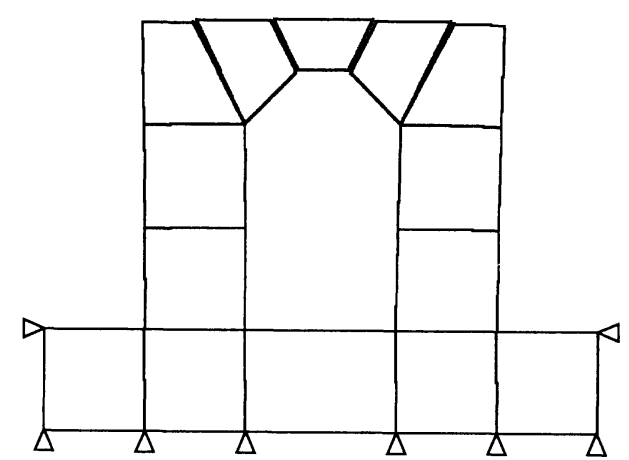

Time step 23 (4.6 seconds)

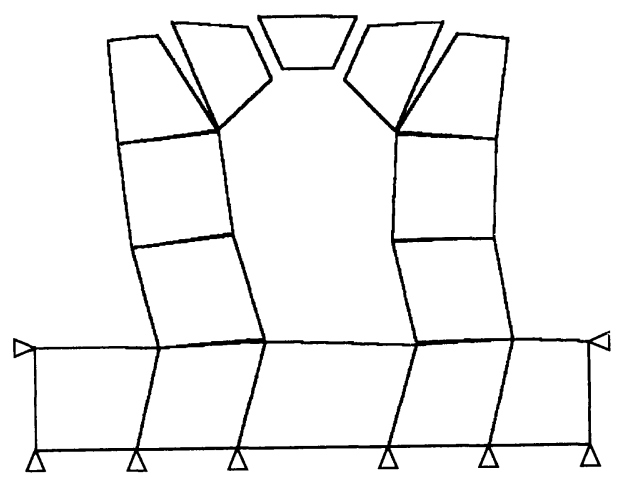

Time step $• 50$ (10 seconds)

(c) Acc. No. 2

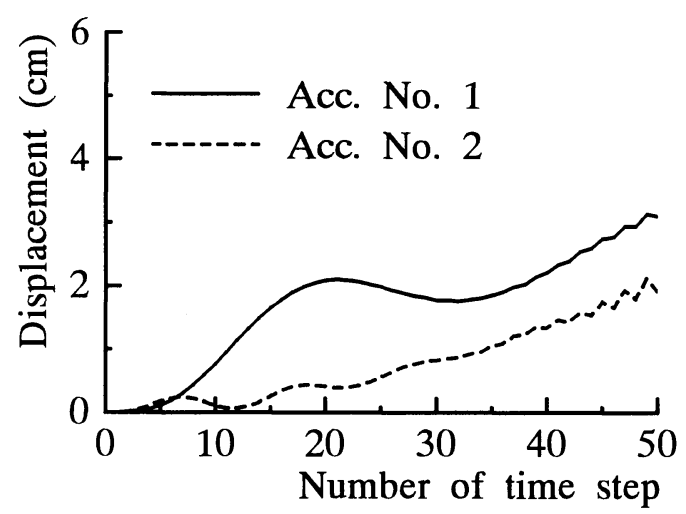

(d) Response at the top most-right corner

Fig. 11 Initial and deformed configurations and displacement response with time of the arch

(10 seconds), the side columns of the arch slide at the base and the arching action disappears while the blocks start to fall apart. As expected, the toppling (failure) modes of the side columns of the arch differ depending on the nature of the imposed form of acceleration waves, as shown in Figs. 11(b) and 11(c) for the time step 50 .

Fig. 11(d) shows the displacement responses with time of a nodal point at the top most-right corner of the arch corresponding to the Acc. No. 
1 and Acc. No. 2. The results in Fig. 11(d) indicates that, as expected, the displacement of the side column of the arch with time is much severe under the Acc. No. 1 as compared with the Acc. No. 2, specially in the early stage of loading.

Figs. 11 (b) and 11(c) show that, under both of the imposed acceleration waves, the reaction of the toppled columns forces the crown block to move upward. This is because of the geometrically symmetric configuration of the structure and outward inclination of the crown block contact interfaces at the center of symmetry, see Fig. 11(a). As can be realized by examining the displacement response curves in Fig. 11(d), the real value of the upward displacement is very small as compared with the dimension of the crown block. It should be noticed that in Figs. 11(b) and 11(c), the displacement is amplified using the illustration scale factor (50 times the actual scale) to make the failure mode of the whole structure more visible.

Although the examples discussed above are very simple structures, they illustrate the fundamental features of the developed DFEM. It is also possible to consider and analyze more complicated masonry structures by the DFEM. Nevertheless, more experimental information is required on the constitutive parameters of blocks and contacts before conducting the analysis of such structures.

\section{CONCLUSIONS}

The present paper contains some computational results of a research program aiming at development of rational and robust numerical techniques for the analysis of masonry structures. At this stage, a technique based on the finite element method incorporating the contact element to model block interactions, called discrete finite element method (DFEM), is considered. The DFEM was applied to study the response of masonry structures under static and dynamic loading conditions. It is found that the DFEM is a promising method for studying the mechanism of masonry structures. The following conclusions have been drawn from this study:

- The suggested scheme calculates displacements at the joints as well as deformation within the blocks, which can be used to follow the processes of the failure mechanism of blocky structures under static as well as dynamic loading.

- The scheme is entirely based on the finite element method and it has been shown that the proposed method is capable of simulating large displacement of blocky systems, such as masonry walls, arches and towers.

- The proposed hyperbolic scheme is still in its formative phase for which both experiments on viscous characteristics of blocks and contacts as well as numerically stable time-discretisation scheme are felt to be necessary.

Although the examples given here are very simple structures, they demonstrate the fundamental features of the DFEM. It is also possible to consider and analyze more complicated masonry structures by this method. However, more experimental data are necessary on the constitutive parameters of blocks and contacts before performing the analysis of such structures. The authors believe that the DFEM could be of some help to researchers and engineers as an engineering computational tool to understand the mechanism of masonry structures as well as to develop methods for the earthquake resistant design of such structures.

\section{REFERENCES}

1) Hoek, E. and Bray J.W.: Rock Slope Engineering, Revised Second Edition, London, the Institution of Mining and Metallurgy, 1977.

2) Aydan, Ö., Shimizu, Y. and Ichikawa, Y.: The effective failure modes and stability of slopes in rock mass with two discontinuity sets, Rock Mechanics and Rock Engineering, Vol. 22(3), pp. 163-188, 1989.

3) Goodman, R.E., Taylor, R. and Brekke, T.L.: A model for the mechanics of jointed rock, J. of Soil Mechs. and Found. Eng. Div., ASCE, SM3, Vol. 94(3), pp. 637-659, 1968.

4) Ghaboussi, J., Wilson, E.L. and Isenberg, J.: Finite element for rock joints and interfaces, $J$. of Soil Mechs. and Found. Eng. Div., ASCE, SM10, Vol. 99(10), pp. 833-848, 1973.

5) Aydan, Ö., Ichikawa, Y. and Kawamoto, T.: Numerical modeling of discontinuities and interfaces in rock mass, Proc. of the $4^{\text {th }}$ Symposium on Computational Mechanics, JSTA, pp. 40-46, 1990. 
6) Cundall, P.A.: A computer model for simulating progressive, large-scale movements in blocky rock systems, Proc. Int. Symp. on Rock Fracture, II-8, Nancy, France, 1971.

7) Shi, G.H.: Discontinuous deformation analysis: a new numerical model for the statics and dynamics of block system, PhD thesis, Dept. of Civil Engineering, University of California, Berkeley, 1988.

8) Mamaghani, I.H.P.: Numerical analysis for stability of a system of rock blocks, Master thesis, Department of Civil Engineering, Nagoya University, Nagoya, Japan, March 1993.

9) Mamaghani, I.H.P., Baba, S., Aydan, Ö. and Shimizu, Y.: Discrete finite element method for blocky systems, Proc. of the Eighth Int. Conf. on Computer Methods and Advances in Geomechanics (IACMAG), Morgantown, USA, Vol. 1, pp. 843-850, 1994.

10) Mamaghani, I.H.P., Aydan, Ö and Kajikawa, Y.: Modeling and analysis of masonry structures, Proceeding of the annual meeting, JSCE, Chubu branch, 115-116, March 1997.

11) Mamaghani, I.H.P., Aydan, Ö and Kajikawa, Y.: Application of the discrete finite element method to seismic analysis of masonry structures, Proceeding of the annual meeting, JSCE, Chubu branch, 95-96, March 1998.

12) Aydan, Ö., Mamaghani, I.H.P. and Kawamoto, T.: Applications of Discrete Finite Element
Method (DFEM) to Rock Engineering Structures, NARMS'96, 2nd North American Rock Mechanics Symposium Tools and Techniques in Rock Mechanics, Canada, 2039-2046, 1996.

13) Aydan, Ö., Ichikawa, Y., Ebisu, S., Komura, S. and Watanabe, A.: Studies on interfaces and discontinuities and an incremental elasto-plastic constitutive law, Proc. Int. Conf. Rock Joints, ISRM, pp. 595-601, 1990.

14) Aydan, Ö. and Kawamoto, T.: Discontinuities and their effect on rock masses, Proc. Int. Conf. on Rock Joints, ISRM, Loen, pp. 149-156, 1990.

15) Aydan, Ö. and Shimizu, Y.: Surface morphology characteristics of rock discontinuities with particular reference to their genesis, Fractography: fracture topography as a tool in fracture mechanics and stress analysis, Geol. Soc. Special Publication, Vol. 92, pp. 11-26, 1995.

16) Mindlin, R.D.: Compliance of elastic bodies in contact, J. of Appl. Mech., Vol. 16, pp. 259-268, 1949.

17) Ngo, D. and Scordelis, A.C.: Finite element analysis of reinforced concrete beams, Journal of ACI, pp. 152-163, 1967.

18) Aydan, Ö., Akagi, T., Ito, T., Ito, J. and Sato, J.: Prediction of deformation behavior of a tunnel in squeezing rock with time dependent characteristics, 5th Int. Symp. on Numerical Models in Geomechanics, NUMOG V, pp. 463-469, 1995.

(Received May 30, 1998)

\title{
個別有限要素法による静的および動的荷重下での石・棟瓦構造物の解析
}

\author{
Iraj H.P. MAMAGHANI • Ömer AYDAN・梶川 康男
}

\footnotetext{
本研究では，個別ブロックからなる石積土木構造物の静的および動的安定性について，有限要素 法に基づく接触要素を取り入れた個別有限要素法を提案し，その定式化を行った. 個別有限要素法で は，石積土木構造物を個別ブロックの集合体として扱い，それぞれの個別ブロックをソリッド要素と してモデル化する．さらに，ブロック間のすべりや分離などの相互作用については，ジョイント要 素，または，境界要素より優れている接触要素を用いてモデル化した．本文では，斜面上に存在する ブロックやアーチ, ピラミッド，壁，塔などの石積構造物について解析し，さらに，本手法の妥当性 を検討するために，他の手法との比較を行った．その結果，本手法がブロック状の集合体の解析の妥 当性を確かめた。
} 